\title{
Post-mining groundwater geochemistry evolution in on the Levikha sulfide deposits of the Middle Urals (Russia)
}

\author{
Liudmila S. Rybnikova ${ }^{1, *}$, and Petr A. Rybnikov ${ }^{1}$ \\ ${ }^{1}$ The Institute of Mining, Ural Division of the Russian Academy of Sciences, Mamin-Sibirjak str. 58, \\ 620075, Ekaterinburg, Russia
}

\begin{abstract}
Mining of volcanogenic copper pyrite deposits of the Middle Urals leads to the rock disintegration, their grinding, increasing the interaction surface. Sulfide minerals are oxidized by interaction with oxygen-enriched meteoric water and secondary minerals are formed (crystallo-hydrates of sulphates, hydroxides). Here technogenic zone hypergene (sulfuric acid weathering crust) is being formed. Once the water pumping activities are finished, the piezometric level recovers its position decreasing the unsaturated zone created during the mining activity, this increases the water-rock ratio increasing the amount of suppliers of sulphates, iron, non-ferrous metals and other elements to groundwater. It defines a low rate of rehabilitation of mining areas after the completion of mining and cessation of dewatering. The regularities of acidic water formation after filling the depression cone are investigated on the abandoned copper mines of the Middle Urals (Russia). The longevity of formation of extremely acidic and polluted waters is determined by the degree of saturation of the supergene zone with secondary minerals and the intensity of water exchange. Seasonal decrease in the component's concentrations $t$ in the period of winter and summer low water was recorded. The unstable character of groundwater components changes with a half-life of more than 5 thousand days is established. The duration of rehabilitation and restoration of groundwater quality will be at least a hundred years.
\end{abstract}

\section{Introduction}

Extraction of sulfidized deposits provokes the appearance of acid mine drainage waters -AMD. Their features are the wide range of $\mathrm{pH}$, high concentrations of sulfate ions, as well as non-ferrous metals and iron, the content of which exceeds the typical underground water cations - calcium, magnesium, sodium. According to [1], the formation of AMD is influenced by many factors, such as: geological (type and structure of the deposit); geochemical (composition of the ore body and host rocks; the presence, quantity and types of sulfide minerals, their shape and size, the presence and volume of potentially

\footnotetext{
Corresponding author: luserib@mail.ru
} 
neutralizing minerals); hydrogeological (properties of the vadose zone and aquifer, groundwater flow rate, flow direction, infiltration intensity); climatic (precipitation, temperature, humidity); technological (technology of mining, intensity of mining operations, methods of processing of minerals, efficiency of extraction of components, stage of development).

The formation of AMD is associated with the dissolution of sulfide minerals. When the level of groundwater decreases by tens and hundreds of meters during the dewatering, a technogenic aeration zone is formed at the mine, oxygen gets free access to the drained part of the rocks and the oxidation-reduction conditions change. This leads to the intensification of oxidative weathering of sulfide minerals.

\section{Processes forming technogenic supergene zone}

In mine workings, collapse zones, dumps, on the pit walls, the processes of hypergenesis actively proceed, technogenic sulfuric acid weathering crust is being formed. There is a significant amount of secondary sulfate crystalline hydrates of sulfate salts of metals such as (in order of formation) melanterite, chalcanthite, coquimbite, rhomboclase, copiapite, halotrichite, etc. [1].

The evolution of sulfuric acid weathering crust occurs gradually, in several stages. At the initial stage, the primary minerals are just beginning to change. Newly formed minerals are few, and they are mainly sulfates, partially oxides and hydroxides. At the middle stage of oxidation, secondary minerals prevail over primary ones, but the most stable sulfides remain in the rocks. The development of the oxidation zone is a consistent continuous chain of changes in the ore substance, which as a result takes the most stable forms in the oxidation zone $[2,3,4]$.

The study of the regularities of groundwater formation and solid phases precipitation during sulfide oxidation was performed on the example of an idealized case of pyrite dissolution in water that is in equilibrium with air oxygen at a temperature $t=10^{\circ} \mathrm{C}$ (simulation was performed using the Visual MINTEQ program code). The system was supposed to include the following components: $\mathrm{H}^{+}, \mathrm{H}_{2} \mathrm{O}, \mathrm{O}_{2}(\mathrm{aq}), \mathrm{SO}_{4}{ }^{2-}, \mathrm{HSO}_{4}{ }^{-}, \mathrm{HS}^{-}$, $\mathrm{H}_{2} \mathrm{~S}(\mathrm{aq}), \mathrm{Fe}^{2+}, \mathrm{FeSO}_{4}^{-}, \mathrm{Fe}^{3+}, \mathrm{FeS}_{2}$ (pyrite), $\mathrm{Fe}\left(\mathrm{SO}_{4}\right) \cdot 7 \mathrm{H}_{2} \mathrm{O}$ (melanterite). The resulting solution has an acid reaction $(\mathrm{pH}=0.4)$ and is supersaturated with melanterite, which precipitates: oxidation of $1 \mathrm{~mol}$ of pyrite leads to the formation of $0.35 \mathrm{~mol}$ of melantarite. The resulting reaction may be written as [5]

$$
\begin{gathered}
1.0 \mathrm{FeS}_{2}+3.45 \mathrm{H}_{2} \mathrm{O}+3.5 \mathrm{O}_{2} \rightarrow \\
0.35 \mathrm{FeSO}_{4} \cdot 7 \mathrm{H}_{2} \mathrm{O}+0.12 \mathrm{Fe}^{2+}+0.53 \mathrm{FeSO}_{4(a q)}+1.10 \mathrm{HSO}_{4}^{-}+0.02 \mathrm{SO}_{4}{ }^{2-}+0.9 \mathrm{H}^{+}
\end{gathered}
$$

With increasing $\mathrm{pH}$ the saturation indices changes: at $\mathrm{pH}<3$ the degree of saturation decreases in the series melanterite $\rightarrow$ goethite $\rightarrow$ jarosite; at $\mathrm{pH}>6$ the series of saturation represented by a sequence: jarosite $\rightarrow$ goethite $\rightarrow$ melanterite. During the melanterite precipitation $\mathrm{Fe}^{2+}$ is consumed for its formation, while $\mathrm{Fe}^{3+}$ appears in appreciable quantity in solution; precipitation of goethite removes $\mathrm{Fe}^{3+}$ from the solution. Thus, in the process of weathering of the main rock-forming minerals, a number of intermediate compounds are formed, the mineral composition in the sequence changes:

$\underset{\text { (pyrite) }}{\mathrm{FeS}_{2}} \rightarrow \underset{\text { (melanterite) }}{\mathrm{FeSO}_{4} \cdot 7 \mathrm{H}_{2} \mathrm{O}} \rightarrow \underset{\text { (jarosite) }}{\mathrm{KFe}_{3}\left(\mathrm{SO}_{4}\right)_{2}(\mathrm{OH})_{6}} \rightarrow \underset{\text { (limonite) }}{\mathrm{KeOOH} \cdot\left(\mathrm{Fe}_{2} \mathrm{O}_{3} \cdot \mathrm{nH}_{2} \mathrm{O}\right)}$




\section{Case study and methods}

Drainage waters at most volcanogenic deposits of the Urals during the mining were characterized by low $\mathrm{pH}$ and increased metal content - up to $\mathrm{n}^{*} 10^{2}-\mathrm{n}^{*} 10^{3} \mathrm{mg} / \mathrm{L}$. A large number of mines in the Middle Urals in recent decades have been closed and flooded. After the completion of mining and the cessation of drainage, the composition of groundwater has changed, acidity has decreased, but they still remain extra- and high metal, strongly acidic and acidic $[6,7]$.

Among the abandoned mines of the Middle Urals, one of the most contrasting in terms of the chemical composition formation of mine waters is Levikha mine. Hydrochemical regularities of transformation of mine waters in the process of flooding (sharply unsteady both hydrodynamic and hydrochemical regime) and after completion of filling of the depression cone (steady-state hydrodynamic regime and sharply unsteady hydrochemical regime at the beginning of the process, quasi stationary during the subsequent period) are considered in detail on the example of the Levkiha mine, for which there is an array of regime information, unique in the duration of observations, completeness of testing and reliability of the results. This facility may be compared with the significance of the research on the Iron Mountain (Colorado, USA), which was carried out by Superfund (US EPA) since the 80th years of the last century [8].

There are several types of groundwater within the landscapes of the abandoned Levikha mine. They connected with the shafts, dumps, collapse zones. The contents of zinc, aluminum, iron, manganese, copper, cadmium, cobalt, sulfur are from two to four orders of magnitude higher than the Clark values. Groundwater discharged to the surface in the collapse zone has maximum values.

\section{Research results and discussion}

The closure of mining activity and the stoppage of water pumping causes the restructuring of the hydrodynamic balance of the mining area, changes in redox conditions, and the development of new hydrogeochemical processes. The groundwater quality is characterized by a significantly unsteady hydrochemical regime. There was a sharp increase in the content of all components within 4-6 months after the release of mine water to the surface (5-6 times compared to the period of mining). Extremely high values have been observed during 3-5 years, followed by a decrease, that may continue for decades or more (Fig. 1). The regularities of copper changes are anomalous both in the maximum values of the concentration coefficients in relation to the period of working out (very low - 0.5), and in a sharp decline in time (less than 1 year).

Groundwater hydrochemistry in the discharge zone is magnesium sulfate bearing waters without bicarbonate and chlorine at the background level of $25-53 \mathrm{mg} / \mathrm{L}$; aluminum, iron, prevail among cations.

The temperature of groundwater is $10^{\circ} \mathrm{C}, \mathrm{Eh}=250 \div 270 \mathrm{mV}$, at this conditions iron is almost completely in the $\mathrm{Fe}^{2+}$ form (measurements in situ). Ranked series in the concentration degree in relation to the mining looks as follows: $\mathrm{K}_{\mathrm{Mg}}>\mathrm{K}_{\mathrm{Mn}}>\mathrm{K}_{\mathrm{Fe}}>\mathrm{K}_{\mathrm{Zn}}>$ $\mathrm{K}_{\mathrm{Al}}>\mathrm{K}_{\mathrm{SO} 4}$. The components content transformation in time is well described by the exponential connection

$$
\overline{\mathrm{C}}=\mathrm{e}^{-\mathrm{bt}}, \quad \overline{\mathrm{C}}=\left(\mathrm{C}_{\mathrm{i}}-\mathrm{C}_{\min }\right) /\left(\mathrm{C}_{\max }-\mathrm{C}_{\min }\right),
$$

where $\bar{C}$ is the relative concentration of the component, $\mathrm{C}_{i}$ is its current concentration, $C_{\min }, C_{\max }$ is its maximum and minimum concentration, respectively. The values of indicator $b$ are $0.13-0.22$ year $^{-1}$, the half-life (decrease of components concentrations by 2 
times) lasts about 5.5 years. To date, the content of chemical components in mine water of the discharge zone is higher than during mining.
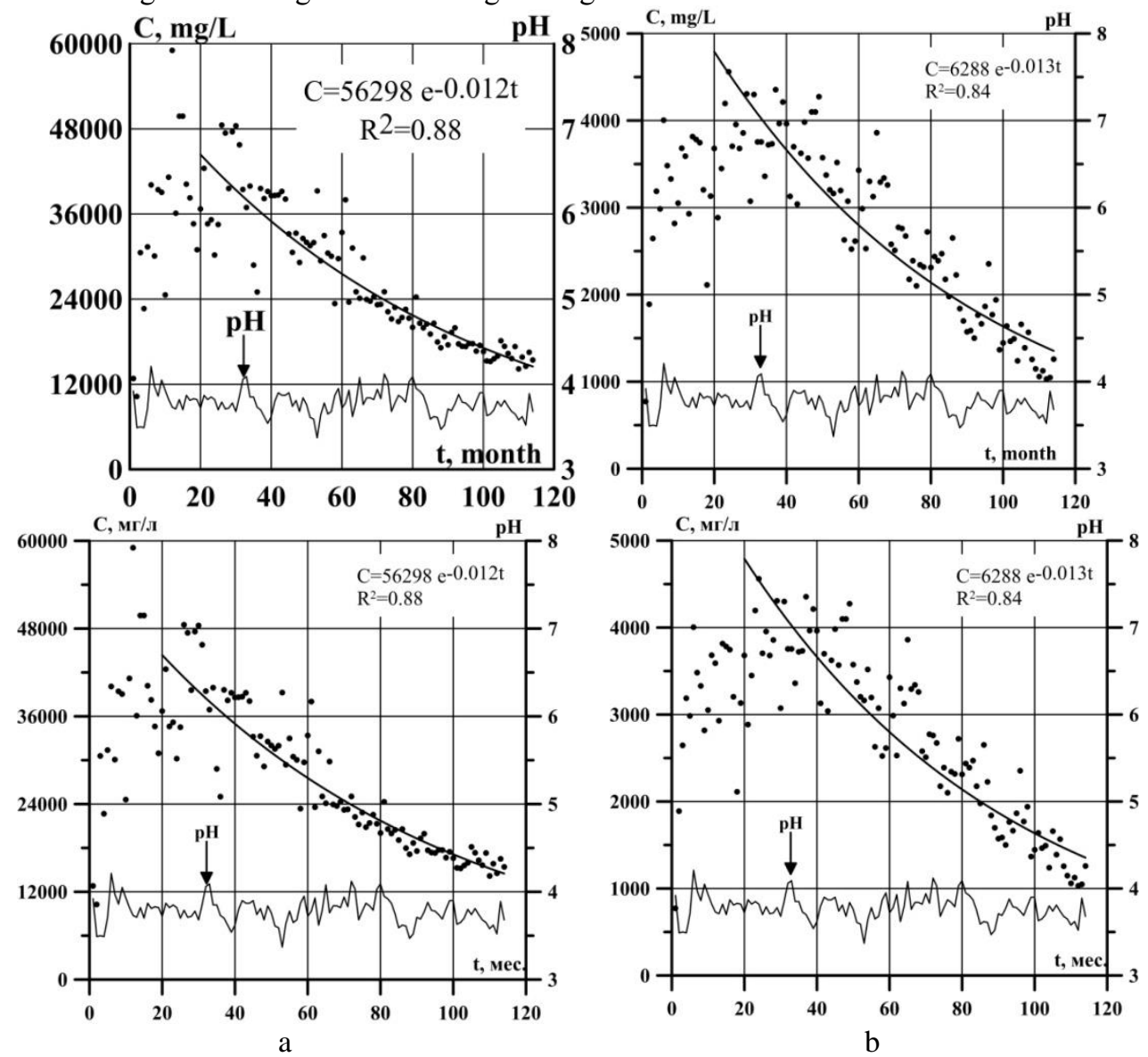

Fig. 1. The components content and $\mathrm{pH}$ changes in groundwater of the discharge zone after flooding (points - sampling data, solid line - exponential approximation, $\mathrm{R}^{2}$ - accuracy of approximation): aTDS, b-iron.

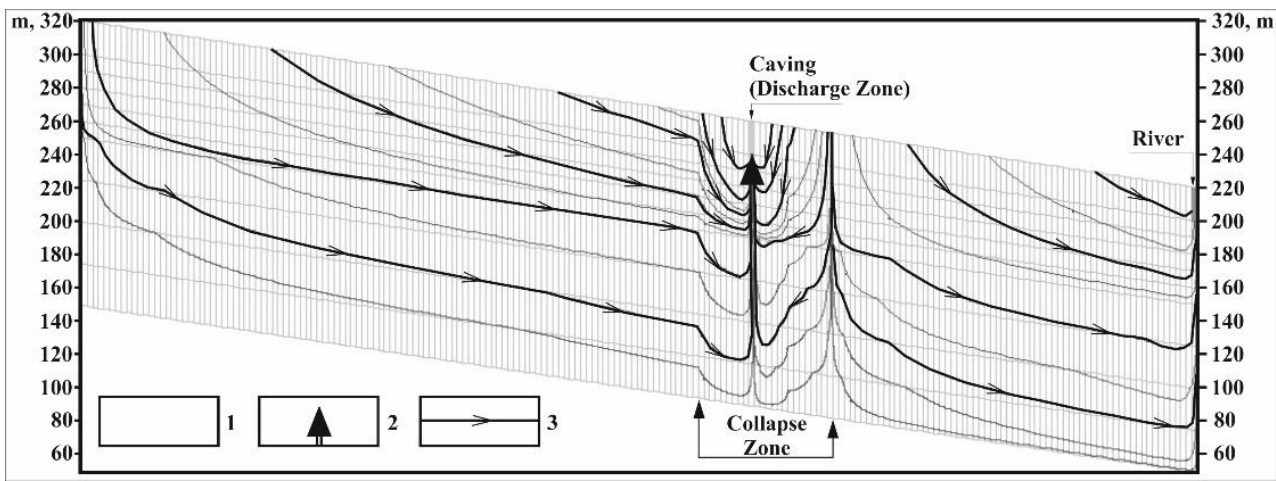

Fig. 2. The scheme of groundwater flow after flooding (on the left - the subsurface watershed, the impermeable boundary; to the right - the river; the block size horizontally - $50 \mathrm{~m}$, the number of layers - 10). 1 - grid layout; 2 - groundwater discharge into the caving; 3 - the direction of groundwater flow (software codes MODFLOW and PMPATH were used). 
TDS concentration increase in the discharge zone, their subsequent decrease (first flush) and regularities of formation of hydrogeochemical systems as a result of redistribution of chemical elements can be explained using the results of thermodynamic and hydrogeomigration modeling.

The groundwater discharge into the caving (discharge zone) consists of the flow that forms in the collapse zone and the lateral flow coming from adjacent areas (Fig. 2). During flooding the secondary minerals formed in the sulfuric acid weathering crust dissolve. The solution in cracks and pores is saturated with sulphates, metals and other components. Groundwater, discharging into the caving, contains high elevated concentrations of dissolved substances due to the water of the collapse zone.

The time of groundwater flow in the collapse zone (from its border to the center of discharge) is 3-5 years. There are extremely high values of almost all components in the technogenic reservoir during this period. The increased values of the components in the initial period of flooding are provided by the flow of the solution from the collapse zone. Over time, the lateral flow coming from the surrounding areas begins to dilute the solution in the collapse zone. This leads to a decrease of the concentrations in the discharge zone, but the formation of acidic waters in this zone will continue for at least 50 years (Fig. 3).
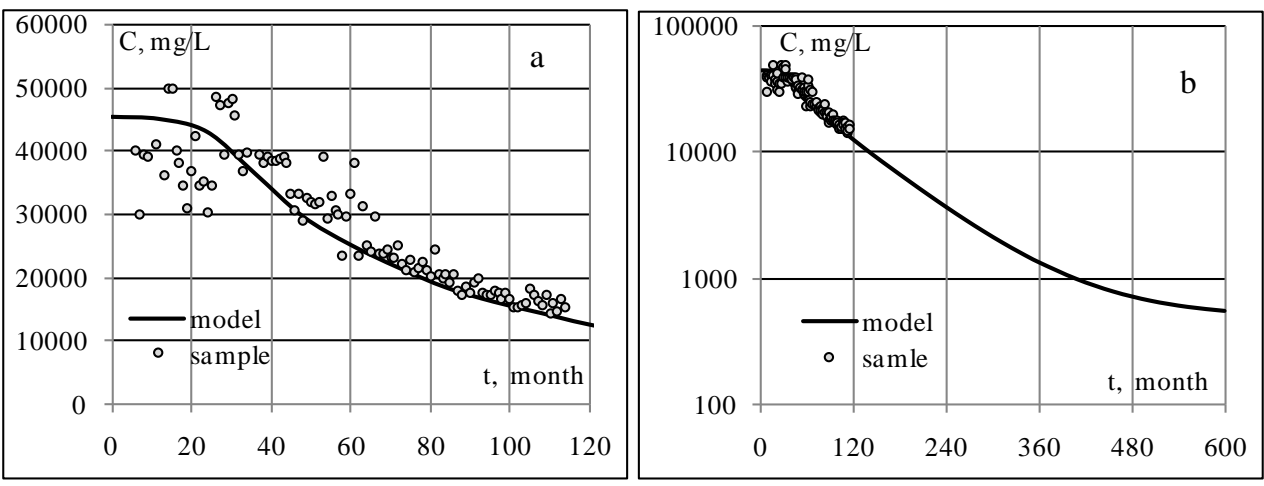

Fig. 3. TDS in the discharge zone, sampling data and simulation results: a - during 10 years after the groundwater discharge to the surface; $b$ - the forecast for 50 years.

The amount of dissolving minerals reaches 5-10 thousand tons per year, while more than one thousand cubic meters of voids are formed in the underground space annually. This is the reason that the formation of new failures in the abandoned mines continues for many years.

The studies were performed in the framework of fundamental research programme of the RAS (No. 0405-2018-0015, No. 0405-2015-0011).

\section{References}

1. D.K. Nordstrom, C.N. Alpers, Proc. Natl. Acad. Sci. USA, 96, 8 (1999)

2. M.C. Moncur, Waterloo, Ontario, Canada (2015)

3. S.S. Smirnov, Moscow, Academy of Sciences, 334 (1951)

4. E.V. Belogub, E.P. Shcherbakova, N.K. Nikandrov, Moscow, Nauka (2007)

5. L.S. Rybnikova, P.A. Rybnikov, Geochemistry intern. (to be published)

6. L.S. Rybnikova, P.A. Rybnikov, Geoecology, eng. geol., hydrogeol., geocryol., 4, 15 (2018) 
7. L.S. Rybnikova, P.A. Rybnikov, Procedia Earth and Planetary Science, 17, 4 (2017)

8. D.K. Nordstrom, Appl. Geoch., 26, 15 (2011) 